\title{
Differential Stains for Identification of Normal and Pathological Hard Tissues using Hematoxylin and Eosin, Masson's Trichrome, and Modified Gallego's Stains: A Comparative Study
}

\author{
${ }^{1}$ Preeti Singh, ${ }^{2} \mathrm{~K}$ Shwetha Nambiar, ${ }^{3}$ Vanishree C Haragannavar, ${ }^{4}$ Dominic Augustine, ${ }^{5}$ SV Sowmya, ${ }^{6}$ Roopa S Rao
}

\begin{abstract}
Aim: The diagnosis of odontogenic tumors and other fibroosseous lesions could be challenging. Use of routine histological staining procedures like hematoxylin and eosin (H\&E) may not aid in providing insight into the nature and character of the hard tissues, thereby require advanced diagnostic aids like immunohistochemistry (IHC), which is technique-sensitive and expensive. Masson's trichrome (MT) stain and modified Gallego's (MG) stain can differentially stain hard tissues, such as tooth, bone, and other pathologic calcifications. The study aims to differentially stain various hard tissue structures present in normal teeth and hard tissue pathologies and compare between the routine stain H\&E, MT, and MG stains. Study of oral hard tissues, comparing $\mathrm{H} \& \mathrm{E}, \mathrm{MT}$, and MG stains is the first of its kind according to our knowledge.
\end{abstract}

Materials and methods: A total of 30 paraffin-embedded tissues were taken from the archives of the Department of Oral Pathology and Microbiology including 15 normal hard tissue structures comprising of 5 decalcified sections of teeth, 5 ground sections of teeth and 5 decalcified section of normal bone. Fifteen histopathologically diagnosed cases of hard tissue lesions/odontogenic lesions (odontome 3 , cemento-ossifying fibroma 5 , cementoblastoma 5 , and central ossifying fibroma 2) were taken. Three sections were taken from each tissue block and subjected to H\&E, MT, and MG stains.

Results: Slides when stained with MG stain, enamel stains pink, dentine stains light green, cementum stains red, and bone stains dark green. Clinically significant result was obtained in case of modified Gallego's stain (0.001). MG > MT>H\&E: $75>50>45 \%$ respectively, in comparison with other two stains. The shade of color differs with the amount of mineralization of the hard tissues. For statistical analysis, chi-square test was employed.

Conclusion: Among $\mathrm{H}$ and $\mathrm{E}, \mathrm{MT}$, and MG stains, MG stain could be a promising differential stain in hard tissue pathologies and other fibro-osseous lesions with diagnostic dilemmas.

Clinical significance: MG stain helps in diagnosis of ambiguous lesions, detection of origin/nature of lesions, differentiation of aggressive and nonaggressive lesions, thus enabling

${ }^{1-6}$ Department of Oral Pathology and Microbiology, Ramaiah University of Applied Sciences Bengaluru, Karanataka, India

Corresponding Author: Preeti Singh, Department of Oral Pathology and Microbiology, Ramaiah University of Applied Sciences, Bengaluru, Karanataka India, Phone: +919739140212, e-mail: singhpreeti7389@gmail.com clinicians to know their biological behavior and plan adequate treatment.

Keywords: Hard tissues, Masson's trichrome stain, Mineralization, Modified Gallego's stain.

How to cite this article: Singh P, Nambiar KS, Haragannavar VC Augustine D, Sowmya SV, Rao RS. Differential Stains for Identification of Normal and Pathological Hard Tissues using Hematoxylin and Eosin, Masson's Trichrome, and Modified Gallego's Stains: A Comparative Study. World J Dent 2018;9(5):372-376.

Source of support: Nil

Conflict of interest: None

\section{INTRODUCTION}

Staining is an auxiliary technique used in microscopy to enhance contrast in the microscopic images. Differential staining is a staining process that uses more than one chemical stain that helps to differentiate between different structures, thus enabling an easy diagnosis.

Identification of structures becomes difficult when many hard tissues are present in the same pathological lesion, resulting in diagnostic difficulties. Diagnosis of such lesions could be challenging in routine staining procedure using H\&E stain. The MT stain is basically known for collagen staining, but in the present study, it is used as differential stain for hard tissue components of pathological lesions. As the name implies, three dyes are employed for selective staining of tissues. The mechanism of staining depends upon the porosity of tissue, as less porous tissue is colored by smallest dye molecule. The MG stain is a variant of Lillie's stain that uses basic reagents like hematoxylin, carbol fuchsin, light green, and aniline blue. This stain is used to differentially stain the hard tissues present in pathological lesions. The present study helps in identification of histological features of pathologies involving hard tissue of oral cavity. The study of oral hard tissues, comparing H\&E, MT, and MG stain present in normal teeth, bone, and pathological lesions is the first of its kind.

\section{MATERIALS AND METHODS}

A total of 30 paraffin-embedded tissue were taken from archives that had calcified components including 
15 which were normal teeth and bone as control (5 decalcified sections of teeth, 5 ground section, and 5 normal bone) and 15 histopathologically diagnosed cases of hard tissue pathologies/odontogenic lesions comprising of odontome (3), cemento-ossifying fibroma (5), cementoblastoma (5), central ossifying fibroma (2). Three sections were taken from each tissue block and stained with H\&E, followed by MT and MG stain. Routine procedures were employed for $H \& E$ and MT, whereas MG stain was further modified during following steps:

\section{Staining Procedure for Modified Gallego's Stain}

- Deparaffinize the sections.

- Stain in hematoxylin for 15 to 18 minutes.

- Rinse in distilled water.

- Stain in mordant for 2 minutes [mix $200 \mathrm{~mL}$ of distilled water in $1.5 \mathrm{~mL}$ of concentrated nitric acid with $1 \mathrm{~mL}$ of $40 \%$ formaldehyde and $1.5 \mathrm{~mL}$ of unique selling point (USP) iron chloride].

- Stain with $5 \mathrm{~mL}$ of carbol fuchsin in $50 \mathrm{~mL}$ of $0.4 \%$ acetic acid and rinse with distilled water.

- Wash with mordant for 1 to 2 minutes.
- Stain with $0.01 \%$ aniline blue in saturated picric acid with 2 mL light green for 5 minutes.

- Dehydrate and clear with xylene, and mount in distyrene, plasticizer, and xylene (DPX) mounting media. Further modification was done for MG stain in the 5 th and 7th steps. The modifications were: concentration of acetic acid was increased from 0.2 to $0.4 \%$ in $5 \mathrm{~mL}$ of carbol fuchsin solution followe Tissues with high inorganic content tissue will retain the hematoxylin color staining the tissue pink in color. $\mathrm{d}$ by adding $2 \mathrm{~mL}$ of light green solution in aniline blue and picric acid. Timing for staining in the 7th step was increased from 2 to 5 minutes. When tissues were stained with these modification, intensity and contrast were better which helped the identification of structures more accurately.

\section{RESULTS}

The histopathological diagnosis after H\&E staining was correlated with MT and MG staining (Figs 1 and 2 and Table 1). Thus, stained slides were analyzed using the following criteria to draw comparison of three stains:

- Reconfirmation (identification and distinguishability)

- Intensity
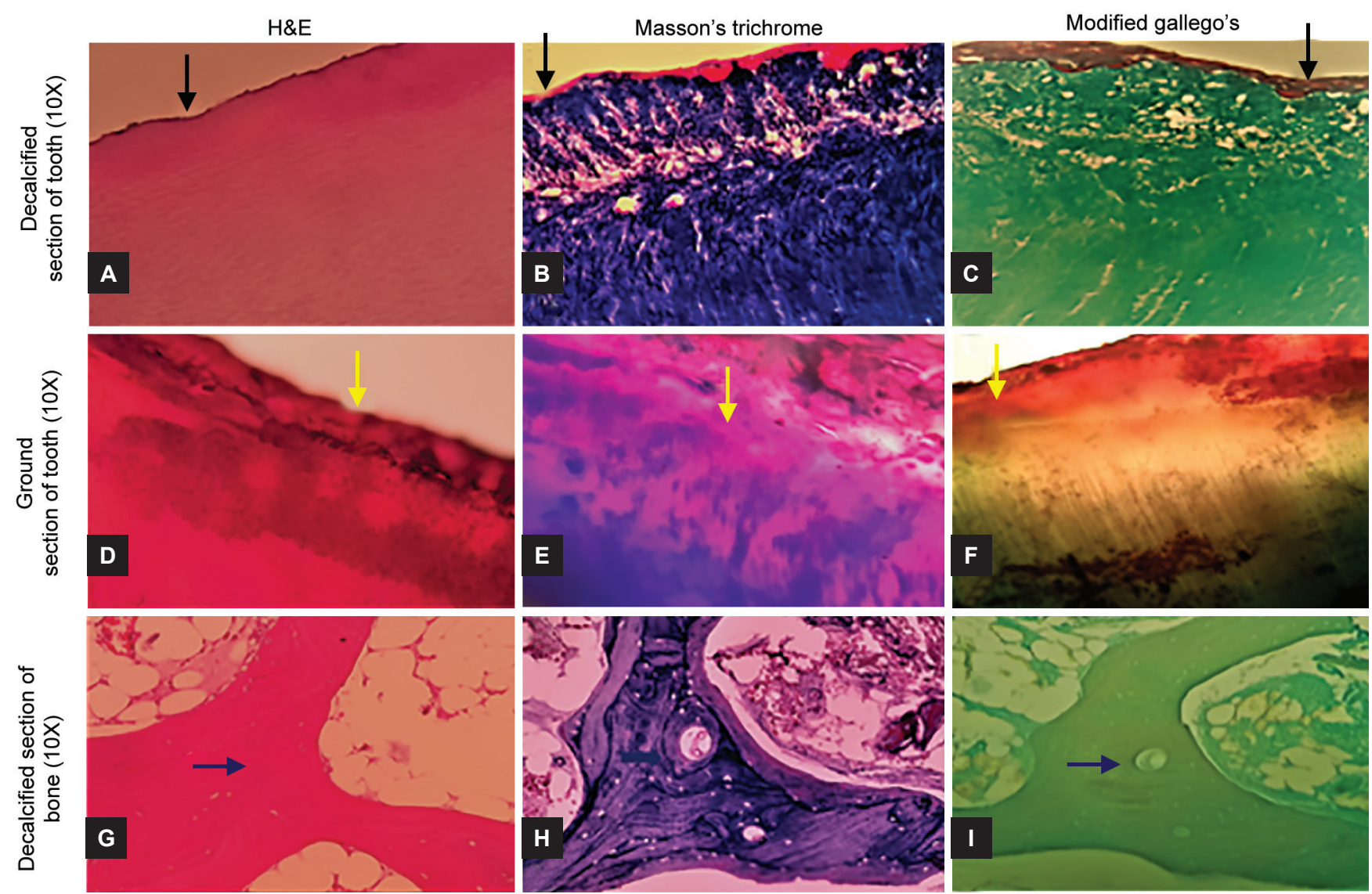

Figs $1 \mathrm{~A}$ to I: Photomicrograph showing different hard tissue components of teeth. (A) Decalcified section of teeth (H\&E), (B) decalcified section of teeth (MT), (C) decalcified section of teeth (MG), (D) ground section of teeth (H\&E), (E) ground section of teeth (MT), (F) ground section of teeth (MG), $(\mathrm{G})$ decalcified section of bone (H\&E), $(\mathrm{H})$ decalcified section of bone (MT), (I) decalcified section of bone (MG). Black arrow: Cementum; Yellow arrow: Enamel; White arrow: dentin; Blue arrow: Bone 


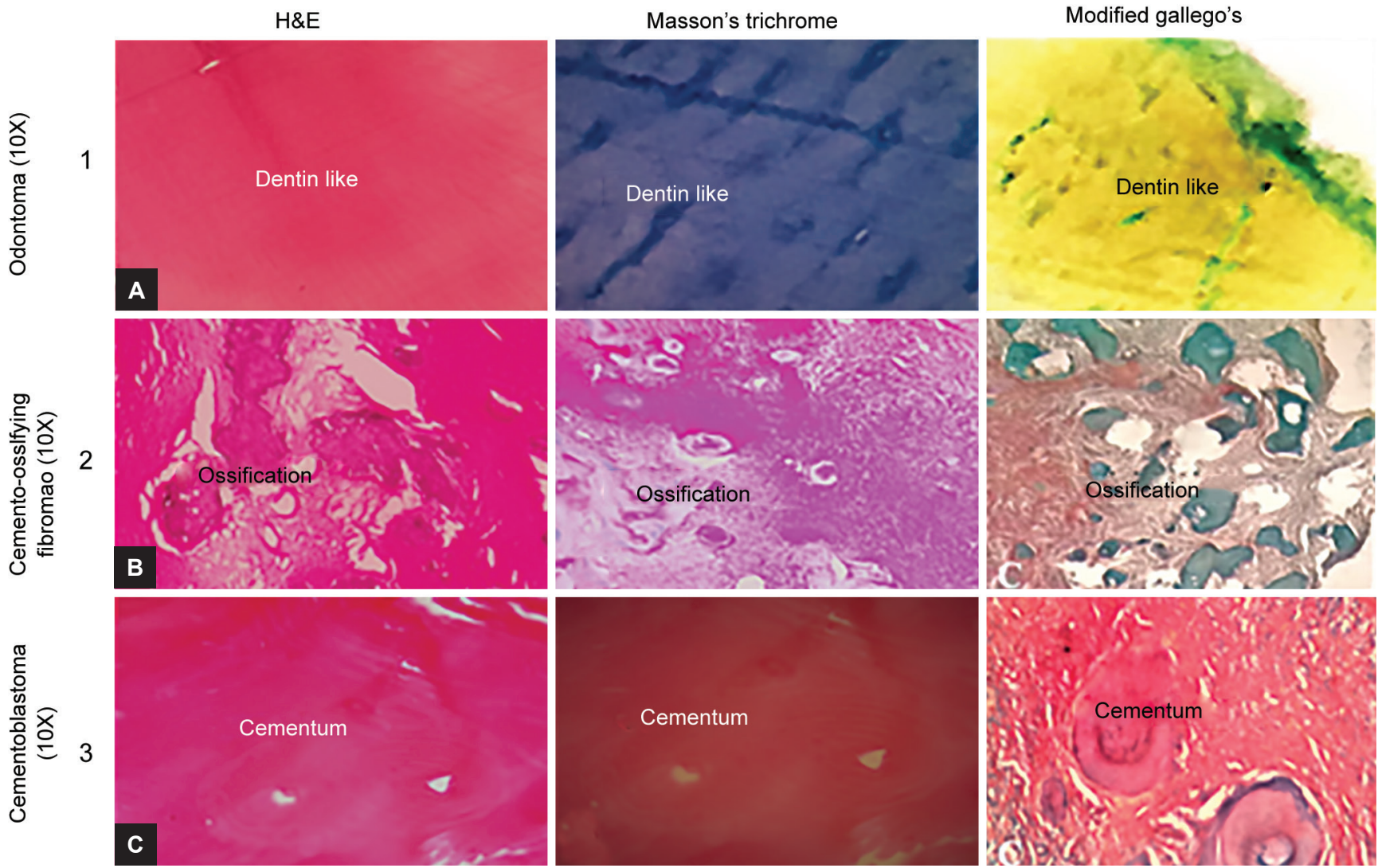

Figs $2 A$ to $C$ : Photomicrographs showing hard tissue pathologies. (A) odontoma dentin-like material stained with H\&E, MT, and MG, (B) cemento-ossifying fibroma ossifying area stained green in MG, (C) cementoblastoma cementum stained red in color with MG

Table 1: Interpretation of nature of calcification using MG stain in normal and pathologic lesions

\begin{tabular}{|c|c|c|c|}
\hline $\begin{array}{l}\text { Hard tissue } \\
\text { components } \\
\text { (decalcified } \\
\text { section) }\end{array}$ & Color & Pathologic Lesions & Color \\
\hline \multirow[t]{2}{*}{ Enamel } & Pink & $\begin{array}{l}\text { Odontoma } \\
\text { (compound) }\end{array}$ & Light green \\
\hline & & Dentin like & \\
\hline \multirow[t]{2}{*}{ Dentin } & Light green & Cementoblastoma & Red \\
\hline & & Cementum & \\
\hline \multirow[t]{3}{*}{ Cementum } & Red/magenta & $\begin{array}{l}\text { Cemento-ossifying } \\
\text { fibroma }\end{array}$ & \\
\hline & & Cementum & Red \\
\hline & & Bone & Dark green \\
\hline Bone & Dark green & & \\
\hline
\end{tabular}

Table 2: Semi-quantitative assessment using a $4^{\circ}$ scale

\begin{tabular}{lllll}
\hline Qualitative value & Poor & Satisfactory & Good & Excellent \\
\hline Numerical value & 1 & 2 & 3 & 4
\end{tabular}

- Contrast

- Preservation and traceability of structures.

The analysis was done using $4^{\circ}$ scale in which if any one of the criteria was present, a numerical representation was given as 1 and poor as qualitative score; similarly, 2, 3,

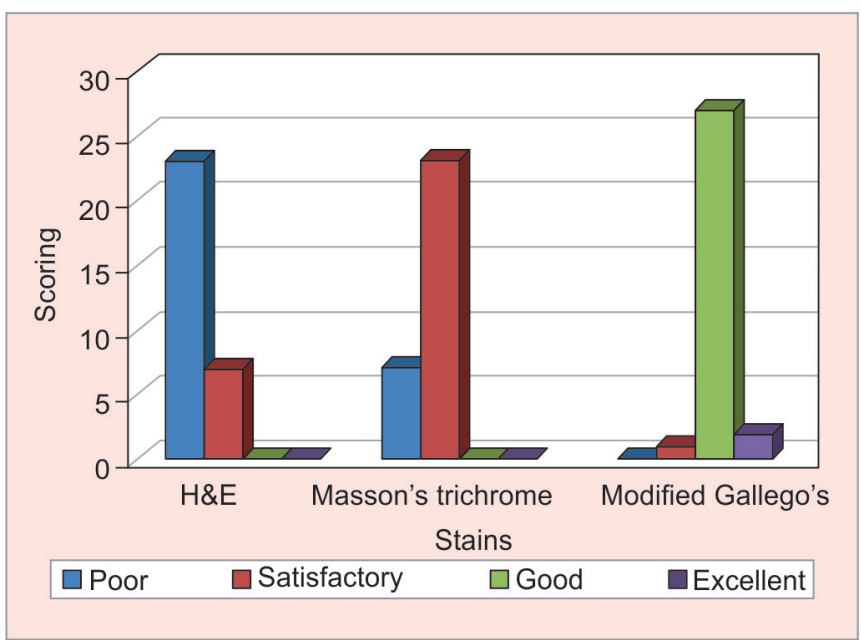

Graph 1: Comparison between H\&E, MT, and MG

and 4 were scored satisfactory, good, excellent respectively (Table 2). For statistical analysis, chi-square test was employed. Clinically significant value (0.001) was obtained for MG stain in comparison with other two stains. The percentage value for each stain was calculated by adding the total score of individual stain divided by the total score 120 and converted into percentage. Thus, we obtained a result of MG $>$ MT $>$ H\&E: $75>50>45 \%$ respectively. The obtained statistical value is represented in Graph 1. 


\section{DISCUSSION}

The H\&E stain is most commonly used stain in histology. Eosin is an acid dye, whereas hematoxylin, though not a basic dye, has staining properties that closely resemble those of a basic dye, so the term basophilia is used in conjunction with hematoxylin staining.

It is used with a mordant, i.e., an intermediate link between the tissue component and the dye, and it is due to the mordant that hematoxylin staining resembles the staining of basic dye. Basic dyes/hematoxylin reacts with anionic groups of hard tissue components like phosphate groups, giving them a uniform blue color. ${ }^{1-3}$ Although $\mathrm{H} \& \mathrm{E}$ is a universally accepted routine stain, differentiation among hard tissues becomes difficult. Such cases mandate differential stain.

Differential staining is a process that uses more than one chemical stain for better differentiation of different structures. ${ }^{1}$ Varied special stains like von Kossa, Alizarin red stain for bone, picro-thionin stain for dentin, tolulidine blue and alcian blue stain for cementum are available, but the use of single histochemical stain that differentiates between various hard tissues of tooth is rare. ${ }^{4}$ For soft tissue pathologies, there are numerous differential stains that help in diagnosis and differentiation. ${ }^{5}$ Examples of such lesions would be hemangiopericytoma and hemangioma, where reticulin stain, a type of special/differential, plays the role for differentiation. Similarly, in case of early invasive carcinoma, discontinuity/breach of basement membrane can be well appreciated with periodic acidSchiff stain, which is again a type of differential stain.

The MT stain is a known differential stain used to differentiate between collagen fibers and smooth muscle in muscular pathologies. The principle behind the staining is that the less porous tissues are colored by the smallest dye molecule, whereas larger molecule dye will stain more porous tissue. ${ }^{2}$ The purpose of using MT stain in the present study was to know whether it stains differentially different hard tissue components present in oral cavity. In the present study, decalcified section of teeth and bone and ground section of teeth were used. During decalcification, organic content of the hard tissue gets removed and organic component will retain. Basically, collagen is the organic component of both dentin and bone. ${ }^{6,7}$ So, MT stain was able to stain those collagen fibers in different shades of color making the identification easy (Figs 1 and 2).

The MG stain is a variant of Lillie's stain that uses basic reagents hematoxylin, carbol fuchsin, and aniline blue. ${ }^{8,9}$ The principle behind the different colors of hard tissue structures in MG stain is due to the inorganic content of tissue, i.e., inorganic content of tissue is indirectly proportional to the porosity of that tissue. First, the tissue was stained with basic reagent hematoxylin, followed by mordant. The less porous or tissues that that contain high inorganic content will take the color of carbol fuchsin imparting red color. Tissues containing less inorganic content and those that are porous will take the color of counter stain after washing with mordant and present with shades of green. Tissues with high inorganic content tissue will retain the hematoxylin color, staining the tissues, pink in color ${ }^{1-3}$ We encountered problems using routine histological stains like H\&E stain on decalcified section of teeth and bones, as it was difficult to differentiate cementum, osteoid component from calcified woven or lamellar bone. These commonly encountered pathologies of the oral cavity often create diagnostic difficulties. ${ }^{8,9}$ In the present study, MT stain exhibited better contrast of hard tissues in decalcified and ground sections than H\&E stain under light microscopy with a clear and even background.

Apart from routine H\&E staining, Manish et al. ${ }^{10}$ performed special staining using MT for peripheral ossifying fibroma where it showed the presence of benign fibroblastic proliferation with gradual production of osteoid and its maturation into the woven bone where MT stain helped to differentiate osteoid and mature bone, giving different shades of green color.

In the present study, MG iron fuchsin stain is used as differential stain for hard tissues. Some modification was done in MG stain so that it would tailor to routine needs. The sulfuric acid was replaced by saturated picric acid and the concentration of both aniline blue and picric acid was increased. Timing for the staining with this solution was also increased to 5 to 6 minutes, which provided good contrast and intensity. Our finding with MG stain showed pink-colored enamel, light green-colored dentin, $\mathrm{red} /$ magenta-colored cementum, and dark green-colored bone, which correlated with the finding of study reported by Tamgade et al., ${ }^{8}$ Satheesan et al., ${ }^{9}$ Mudhiraj et al., ${ }^{11}$ and Avinash et al. ${ }^{12}$ The intensity, contrast, identification, and preservation of structures was more appreciable in MGstained sections than MT and H\&E stain.

The MG stain is one such stain that stains not only the decalcified sections but also the calcified structures present in the pathological lesions, and thus aids in obtaining a clear histological picture. In the case of chondroblastic variant of osteosarcoma and chondrosarcoma de novo, H\&E stain will not give insight into nature of lesion, leading to diagnostic difficulty. In such conditions, MG stain could be used to differentiate histological structures, such as chondroblast from osteoblast. For such cases, appropriate diagnosis is necessary as their biologic behavior and aggressiveness differ, and accordingly, the treatment modality has to be modified. ${ }^{5,13,14}$ The MG stain helps in the diagnosis of ambiguous lesions, detection of origin/nature of lesions, differentiation of aggressive and nonaggressive 
lesions, and thus enables clinician to know their biological behavior and plan adequate treatment. So, MG stain could be a promising differential stain in hard tissue pathologies and other fibro-osseous lesions with diagnostic dilemmas.

Some of the limitations encountered during procedures were that the MG staining was technique-sensitive. Long-term preservation of slides is questionable beyond 6 months due to fading of the stain.

\section{CONCLUSION}

The MG stain was superior in all the aspects like intensity, contract, preservation, and traceability of structure in comparison with H\&E and MT stain, as it is cost-effective, involves single step, and requires less staining time. So, MG stain could be a promising differential stain in hard tissue lesions with diagnostic dilemma.

\section{REFERENCES}

1. Ross MH, Pawlina W. Histology: a text and atlas with correlated cell and molecular biology. Baltimore (MD): Lippincott Williams \& Wilkins; 2006.pp.122-125.

2. Suvarna SK, Layton C, Bancroft JD. Bancroft's theory and practice of histological techniques. China: Elsevier Health Sciences;2012.pp.121-125.

3. Culling CF. Histopathological and histochemical techniques. 3rd ed. London: Butterworth; 1974.pp.63-72.

4. Lillie RD. Histopathologic technique. Philadelphia (PA): The Blakiston Company; 1948.pp.203.
5. Hess JA, Villanueva AR. Differential staining of decalcified teeth and bones by modified Attwood's stain. Lab Med 1983 Jul;14(7):435-438.

6. Kumar GS. Orban's oral histology \& embryology. 13th ed. New Delhi: Elsevier Health Sciences;2014.pp.51-53.

7. Nanci A. Ten Cate's oral histology-pageburst on vitalsource: development, structure, and function. St. Louis (MO): Elsevier Health Sciences;2007. pp.159-165.

8. Tamgadge SA, Tamgadge A, Srivastava C, Satheesan E, Bhalerao S. Modified Gallego's stain as differential stain for oral hard tissues in oral pathology: a preliminary report. Int J Oral Maxillofac Pathol 2014;5(2):2-6.

9. Satheesan E, Tamgadge S, Tamgadge A, Bhalerao S, Periera T. Histopathological and radiographic analysis of dental follicle using modified Gallego's stain. J Clin Diagn Res 2016 May;10(5):ZC106-ZC111.

10. Manish S, Sharma Gaganjot K. Peripheral ossifying fibromaa masquerade. Ann Dent Res 2012 Sep;2(1):36-43.

11. Mudhiraj PV, Vanje MM, Reddy BN, Ahmed SA, Suri C, Taveer S, Kumar S. Nature of hard tissues in oral pathological lesions - using modified Gallego's stain. J Clin Diagn Res 2017 Apr;11(4):ZC13-ZC15.

12. Avinash T, Sandhya T, Gokul V, Neha T, Snehal D. Juvenile cemento-ossifying fibroma: a case report using modified Gallego's staining. Int J Res Med Sci 2016 Feb;4(2):658-661.

13. Chaudhary M, Chaudhary SD. Osteosarcoma of jaws. J Oral Maxillofac Surg Med Pathol 2012 May-Aug;16(2):233-238.

14. Rajendran R. Cysts and tumors of odontogenic origin. In: Rajendran R, Sivapathasundharam B, editors. Shafer's textbook of oral pathology. 6th ed. Noida: Elsevier;2009. pp.282-283. 